University of Minnesota Morris Digital Well

University of Minnesota Morris Digital Well

\title{
Nonconscious Motivational Influences on Cognitive Processes in Addictive Behaviors
}

Eric Klinger

University of Minnesota - Morris, klinger@morris.umn.edu

W. Miles Cox

Javad S. Fadardi

Follow this and additional works at: https://digitalcommons.morris.umn.edu/psych_facpubs

Part of the Human Factors Psychology Commons

\section{Recommended Citation}

Cox, W.M., Klinger, E., \& Fadardi, J.S. (2016). Nonconscious motivational influences on cognitive processes in addictive behaviors. In Heather, N. \& Segal, G. (Eds.) Addiction and Choice: Rethinking the relationship (pp. 259-285). New York: Oxford University Press.

This Book Chapter is brought to you for free and open access by the Faculty and Staff Scholarship at University of Minnesota Morris Digital Well. It has been accepted for inclusion in Psychology Publications by an authorized administrator of University of Minnesota Morris Digital Well. For more information, please contact skulann@morris.umn.edu. 


\title{
Chapter 15
}

\section{Nonconscious motivational influences on cognitive processes in addictive behaviors}

\author{
W. Miles Cox \\ Eric Klinger \\ Javad S. Fadardi
}

\begin{abstract}
This chapter presents the motivational and goal theory of current concerns in relation to addiction and choice. A current concern is an individual's motivational state from the point of becoming committed to pursuing a particular goal until the goal is reached or the pursuit is relinquished. During this time, the current concern guides the person's cognitive processes, including attention, memory, thoughts, and dreams. What is true of goals in general is true of the goal of drinking alcohol or using another addictive substance. We hold that the decision to use a substance is voluntary; thus, the choice to use is subject to the person's conscious control. Nevertheless, implicit processes influence the decision. One of these processes is addiction-related attentional bias. We describe (1) the research on attentional bias and (2) interventions for helping drinkers overcome the attentional and motivational influences on their addictive behavior.
\end{abstract}

\section{A framework for cognitive processes in addictions: the motivational goal theory of current concerns}

Addicted individuals are characterized by organizing much of their daily lives around assuring supplies of, obtaining, and consuming the subject of their addiction, whether a substance such as alcohol or an activity such as gambling. The goal theory of current concerns provides a useful framework that accounts for many of the aspects of such addiction. The theory (summarized in Klinger and Cox 2011a) has gradually evolved over more than four decades from an initial effort to account for shifts in thought content (Klinger 1971) to explanations for a wide variety of affective (Klinger 1975, 1977), social and psychopathological (Klinger 1977; Klinger and 
McNelly 1969), and cognitive phenomena (e.g. Hoelscher et al. 1981; Nikles et al. 1998; Klinger 1978, 1990, 1996a, 1996b, 2012, 2013; Klinger et al. 1980). Because it rests on a motivational base, it has special relevance to addictive behaviors and their cognitive characteristics.

\subsection{The nature of the goal theory of current concerns}

The theory begins with the realization that what characterizes all members of the animal kingdom during at least some stages (and usually all stages) of their lives is the imperative of locating and consuming the substances and conditions necessary for individual and species survival. In all but the most primitive species, these substances and conditions can be characterized as goals.

Goals are defined here as desired endpoints-attainment of objects or events-that the person is trying to achieve because he or she expects that achieving them will bring emotional payoffs by enhancing positive affect (through appetitive goals of attaining, keeping, or restoring something, such as a job, an achievement, or a relationship) and/or reducing negative affect (through aversive goals aimed at avoiding, escaping, or ridding oneself of something valued negatively, such as an illness, a noisy roommate, or a bill collector). The payoffs may be intrinsic to the outcome, such as a feeling of being loved, or extrinsic in the sense of outcomes being subgoals instrumental in attaining further outcomes that will provide the intrinsic satisfaction (e.g. arranging a date that enables a love relationship, or pleasing one's boss and thus protecting one's job that enables intrinsically satisfying consequences, such as copious tasty food, a nice place to live, and a good marital relationship).

To pursue a goal over more than an instant it is necessary for the brain to have a memory of it and tendencies to act on it under the right circumstances. When a dog sees a squirrel, the dog immediately springs into action chasing the squirrel. If the squirrel flees up a tree, the dog stands by the trunk and keeps barking. Most human goals are more complicated than that, often requiring a sequence of actions on subgoals before arriving at the opportunity to consummate the ultimate intrinsic goal, and often requiring days, months, or years to complete the pursuit. During most of the time period before the opportunity to consummate a particular goal its representation is absent from consciousness. Nevertheless, the individual is likely to give cues associated with it priority for cognitive processing. That is true for the most direct cues, as for instance the name of a beloved person, and also more remote cues, such as allusions to similar personal relationships.

For this to work, the brain must necessarily harbor a continuing representation of the goal and special responsiveness to its cues. We dub this continuing representation a current concern, defined as "the state of the organism between the time of commitment [to the goal pursuit] and the time of consummation or disengagement" (Klinger 1975, pp. 2-3). The construct of current concern explicitly does not refer to the "individual's thoughts or actions during this state" (Klinger 1977, p. 37), which the concern underlies and potentiates. Each goal is represented by its own separate current concern. 
The presumption from the beginning was that the construct refers to a latent goalrelated brain process, whose actual representation in the brain remained unspecifiable until recent neuroscientific advances begun to generate clues (e.g. Berkman and Lieberman 2009; Klinger and Cox 2011a; Kouneiher et al. 2009). This latent process conveys processing priority to goal-related cues in the environment and in the person's own ongoing stream of mentation. The processing entails attention, perceptual processing, retention, and thought content, including both verbal thoughts and nonverbal images. There is now ample evidence of this for waking states, in which experimental investigations using a variety of methods have shown that individuals respond selectively to goalrelated cues with greater attention, retention, and conscious thoughts about the goal (Cox et al. 2006; Klinger 1978, 2013; Leeman et al. 2014; Montagrin et al. 2013), as well as with accompanying emotional responses (Bock and Klinger 1986; Klinger 1996a, 2013; Nikula et al. 1993; Schneider 1987). Similar evidence of processing priority for goal-related cues has been found in dreams during sleep (Hoelscher et al. 1981; Nikles et al. 1998). The goal-related cues that elicit processing may be external, such as in conversations or media, or they may be internal, part of one's ongoing stream of thought. Their enhanced claim on processing priority helps explain the sequencing of the content in that stream.

The cues to which people respond may have only an indirect association with the goal. From birth onwards, people develop an extensive network of associations. Our observations indicate that response is most likely and strongest to cues most directly associated with goals, but it also occurs regularly to more remotely associated cues.

\subsection{The nonconscious nature of current concerns}

The cues introduced to our participants in the thought- and dream-sampling studies cited in Section 1.1 on the nature of the goal theory of current concerns occurred without regard to participants' ongoing mental content at the moment of stimulation, when they would be very unlikely to be focusing on the cued goal. Yet the resulting mental content was disproportionately related to the particular own goals adumbrated by the cues. This supports the notion that the current concern underlying the cued goal is indeed a latent process. In other words, it operates nonconsciously. Its products-attended perceptions, retrieved memories, and mental contents-are often conscious, but these are distinct from the underlying process.

Although not without controversy because of some failures to replicate (Cesario 2014), substantial evidence suggests that existing goal pursuits can be activated nonconsciously by experimental manipulations using priming techniques, such as by introducing goal-related stimuli with no explicit relation to a subsequent task and observing their effects on the subsequent task behavior (e.g. Chartrand and Bargh 1996; Huang and Bargh 2014). Chartrand and Bargh (1996) concluded, "preconscious processing is rich and extensive and capable of activating goals that are chronically associated with features of the current environment. The goals then operate autonomously, without the need for conscious monitoring, and guide subsequent information processing interactively with the environment" (p. 475). Moreover, it appears that, 
regardless of whether a goal pursuit is activated consciously or unconsciously, its activation makes similar demands on executive function (Huang and Bargh 2014; Marien et al. 2012).

Together with the processing priority afforded goal-related cues, such implicit activation of goals, such as through product placement in shops and advertising displays, can impose a considerable burden on addicted individuals who wish to moderate or end their consumption of alcohol. This has been amply demonstrated in relation to heavy drinkers (e.g. Cox et al. 2006). The specifics of the relevant alcohol findings are described in Section 3.2 on the importance of substance-related cognitive biases and Section 4 on forms of cognitive bias.

At this time it is probably unknown whether it is also possible to initiate commitment to a goal without an act of consciousness. Although that seems possible, there are grounds for skepticism, albeit without direct contrary empirical evidence (Moskowitz and Balcetis 2014). The evidence that priming of goals through the use of subliminal stimuli or of seemingly unrelated stimuli can influence behavior in subsequent experimental tasks cannot distinguish between the commitment to new goals for a laboratory exercise versus the activation of pre-existing goals, such as to recall recent events or size up other people. The question of nonconscious commitment thus most likely remains unresolved.

\subsection{Determinants of commitments to goals: the decision process}

Life generally surrounds us with incentives, objects, and conditions that we in varying degrees desire (appetitive or positive incentives) or desire to eliminate (aversive or negative incentives). People must keep choosing among these to turn some of them into goals. Formal models of the decision process for these choices have been around for millennia, but those still widely employed are variants of what economists call subjective utility theory (e.g. Mongin 1997) and psychologists more often call expectancy $x$ Value theory (e.g. Bundorf et al. 2013; Feather 1982; Morone and Morone 2014; Van Eerde and Thierry 1996). Under this model, the transformation of an incentive into a goal is determined primarily by two important variables: the value that the person attributes to the incentive (i.e. how desirable the affective change from obtaining the incentive is expected to be) and his or her expected likelihood of being able to achieve it within an acceptable time frame and at acceptable cost. Theoretically, when a person is faced with needing to choose, the incentive that has the largest product of Expectancy times Value is the one that the individual will choose to pursue. This choice constitutes a commitment to the goal pursuit and instates a current concern that persists until the person attains the goal or relinquishes it if its net value and/or expectancy diminish enough with additional experience of the pursuit. Variants of this model have been applied in recent decades to choices of jobs, crimes, contraceptives, family size, migration, political alternatives, medical alternatives (summarized in Cox, Klinger, and Fadardi 2015), and, notably, binge drinking (Quinlan et al. 2006). 
Especially important for present purposes is the set of factors that determine these choices. Expectancies and values (i.e. anticipated emotions, such as joy at goal attainment and sorrow at goal abandonment) are both affected by psychoactive substances and by a variety of other influences that have also been shown to affect addictive behaviors, including prior mood, social support or disparagement, culturally ingrained expectations, and personality dispositions. Some of these are discussed in Section 3 on the goal of drinking alcohol. People are often unaware of the influence these factors exert on their decision-making.

\section{Disengagement from failed goal pursuits and its implications for addictive behaviors}

It is generally harder to let a goal go in the face of insuperable obstacles than to commit to it. The commitment is probably undertaken in a spirit of hope and expectation; giving up is accompanied by a sequence of affectively negative events (Klinger 1975, 1977, 1993). After goal attainment, cognitive reactivity to goal-related cues diminishes relatively quickly (Förster et al. 2007; Moskowitz et al. 2011). In contrast, failed current concerns, once instated, can probably not simply be terminated. Rather, as in the case of extinction of operant responses, which is a process of inhibitory learning rather than of unlearning the original response (Bouton 2002), ending the sway of a failed current concern is almost certainly a process of progressive extinction of responses to cues, in this case goal-related cues. Just as extinguished responses can be reinstated in a variety of ways without extensive relearning (e.g. Bouton 2002; Haaker et al. 2014), disengagement from goals is often quickly reversed when circumstances become more favorable. This could happen only if the extinguished response or abandoned goal pursuit remains represented in the brain in a form ready to re-emerge.

The disengagement process (incentive disengagement cycle) has been described as a sequence of phases (Klinger 1975, 1977, 1987; Klinger and Cox 2011a) set off by an "action crisis" (Brandstätter et al. 2013) in a goal pursuit as difficulties mount and finally are recognized as insurmountable within acceptable costs. The phases begin with invigorated efforts in the goal pursuit, followed by anger sometimes accompanied by aggression, followed further by lowered mood that may range from disappointment to clinical depression, with marked loss of interest in ordinarily attractive incentives and goals (Klinger 1993), and ending in most cases in gradual recovery with completed disengagement from the failed goal, and re-engagement with other goals. Re-engagement appears to be essential to full recovery (Carver and Scheier 1998; Wrosch et al. 2013). The middle phases of this cycle are especially likely to lead to heavy substance use and other addictions.

A common accompaniment of negative moods during the disengagement process is rumination (e.g. Aldao et al. 2010; Koster et al. 2011), in which the person's thought stream is heavily preoccupied with mostly negatively toned thoughts that focus repetitively on a limited range of personal concerns without arriving at constructive 
solutions. The current concerns theory, as in the preceding paragraph on the incentive disengagement cycle, can readily account for depressive rumination-the continual goal-related contents of ruminative sequences serve as cues that elicit further goal-related contents, especially regarding goals with higher emotional charge. In periods of negative mood, the emotional charge is likely to be negative, especially in individuals high in trait negative affect. The effect of such rumination is generally to deepen depression further (e.g. Marchetti et al. 2012a; Marchetti et al. 2012b; NolenHoeksema et al. 2008).

The implications for addictive disorders, especially substance-use disorders, are extensive. People are drawn to dispel their negative affect during the disengagement cycle with psychoactive substances and perhaps other manipulations of affect such as gambling. During the depression phase, these become more attractive relative to alternative goals as interest in the latter wanes. The withdrawal from nonsubstance goals leads to increased social isolation and correspondingly leads to greater focus on substance use. Furthermore, one can predict somewhat similar implications for people in circumstances that offer little hope of satisfying goal attainments, with the consequence that their lives lose meaning (Klinger 2012). These implications for addictions are discussed later in the chapter.

\subsection{Are addictive behaviors motivated or automatic? a false dichotomy}

The position of this chapter is that addictive behaviors are, like other behaviors beyond simple reflexes, goal-directed and voluntary (see also, e.g., Heyman 2009). Many writers on this topic would have disagreed, arguing that addictive behaviors, or at least some of their components, are "automatic" and beyond voluntary control. The automaticity is perhaps most often applied to attentional biases. The term "automatic" is rarely defined but can be taken to mean having a high probability of occurrence, if not certainty, under given conditions, or of unconscious origin (Huang and Bargh 2014). The term "compulsive" is also used (e.g. Feil et al. 2010), usually to describe addictive instrumental (e.g. "seeking") and consummatory actions (e.g. "taking"; Vanderschuren and Everitt 2005).

The image conveyed by such terms is one of mechanical rigidity. Yet the literature indicates modifiability. For example, alcohol-related behaviors termed as automatic action tendencies can be changed through cognitive bias modification (Wiers et al. 2011) and mindfulness treatment (Ostafin et al. 2012; Witkiewitz et al. 2013). Similarly, there is an extensive literature on successful behavioral modification of obsessive-compulsive behaviors, including the superiority of such treatments to pharmacological treatments (Foa et al. 2005). Finally, there is now substantial evidence that when people change their substance use most of them do so on their own without formal treatment (Bischof et al. 2012; Klingemann 2001; Smart 2007; Sobell et al. 2000).

The present chapter takes the position that addictions reflect processes similar to those that characterize all striving for highly valued goals. Their high value creates the appearance of automaticity. A distinguishing feature of goal-directedness-indeed, one of its operational definitions-has long been considered to be the ability to change tactics in 
the face of obstacles, as was first strongly argued by Wolfgang Köhler (1925). At that time, this flexibility was labeled Umweg (detour) behavior to describe new responses that circumvent obstacles to goal attainment. Detour behavior certainly characterizes the actions of addicts who face obstacles to obtaining their substances, as for instance demonstrated anecdotally in the wily actions of addicted nurses in stealing substances from patients and hospital stores (Stahl 2013). Their goals may appear rigid because of the high value they place on them, but the actions leading up to goal attainment are highly flexible.

Opposing automatization to goal directedness creates a false dichotomy. Of course, frequent repetition of action sequences leads to integration of initially separate action units into longer, relatively seamless action streams that require little conscious control to unfold, as in skilled playing of a musical instrument, driving a car in traffic, or fielding a baseball. However, it is important to realize that this kind of response integration does not create inflexible automatons. Even integrated action sequences are subject to modification depending on circumstances. The guitarist may change specific fingering to accommodate a suddenly broken string, the driver can adjust to the need to take a detour, and the fielder's movements will vary according to the wind, other players, or an unexpected bounce-all in the service of attaining their respective goals. The integrated action sequences remain aimed at these goals, potentially under conscious control.

As indicated in Section 1.2 on the nature of current concerns, alcohol addicts are marked by attentional biases that steer them to alcohol cues, which in turn further whet appetites for alcohol consumption, along with a variety of other cognitive biases, including heightened delay discounting (discussed in Section 3.2.1 on incentive comparison effects; see also Noël et al. 2010). Some of these are biases developed by pursuers of any highly valued goal; others may represent ingrained individual differences in brain function or the acute effects or chronic after-effects of substance use. They influence decisionmaking about priorities, sometimes very maladaptively, but tap variants of the kinds of interactive neurocognitive systems active in most decision-making (Noël et al. 2013).

Finally, it should be noted that the theory presented here has some features in common with dual-process models of addiction (e.g. Moss and Albery 2009; Wiers et al. 2007). These models assume that both automatic processes (e.g. addiction-related attentional bias and approach tendencies) and controlled processes (i.e. deliberate responses) are involved in addictive behaviors. We agree with this general position. The theory of current concerns acknowledges that both kinds of processes can influence decisions about whether or not to use an addictive substance; nevertheless, in our view, the decision is always under the person's voluntary control so that controlled processes can always override the automatic processes.

\section{The goal of drinking alcohol}

Here we depict excessive alcohol consumption as an example of an addictive behavior. However, the main principles underlying the goal of drinking alcohol could be applied to other kinds of substance abuse and other kinds of addictive behaviors. 
Many people, of course, do not drink alcohol. Among those who do drink, some people drink moderately; others drink excessively, and the latter might experience various degrees of alcohol-related problems. Regardless of its intensity, the goal of drinking alcohol is formed in the same way as any other goal, consistent with value X expectancy theory as discussed in Section 1.3 on determinants of commitments to goals. It is determined largely by (1) the value that the person attributes to drinking and (2) the person's expected chances of being able to derive the desired benefits from drinking versus being able to obtain comparably satisfying benefits by other means.

This generalization regarding value $\mathrm{X}$ expectancy determinants of alcohol consumption is supported, for example, by the finding in a four-country study (Cox et al. 2002) that, among students who had experienced negative consequences from drinking, there was inverse correlation between adaptive motivation and amount of alcohol currently consumed. In view of the factor structure of adaptive motivation (e.g. Klinger and Cox 2011b) - with high loadings on joy anticipated from attainment of one's goals (i.e. value) and expected probability of attainment (i.e. expectancy) - adaptive motivation is a reasonable proxy for having satisfying and attainable goals that are alternative to drinking alcohol. Apparently, the more that participants had such goals, the more they were able to curb their drinking when it interfered with their attaining the goals.

There are various ways in which benefits can be derived from drinking alcohol. First, they can be derived directly from the pharmacological effects of the alcohol. For example, because of its effects on neurotransmitters in the brain (Tabakoff and Hoffman 2013), alcohol might serve intrinsically to reduce tension or anxiety (through the release of gamma-aminobutyric acid (GABA)), or it might enhance incentive salience of reward-related stimuli (through the release of dopamine; Berridge 2007). Second, they can be derived indirectly-or instrumentally, extrinsically-because drinking alcohol allows the person access to other valued incentives, such as approval from his or her peers.

The various intrinsic and extrinsic determinants of drinking alcohol-the biological, psychological, and sociocultural variables-have been brought together in the motivational model of alcohol use (Cox and Klinger 1988, 2011a; Cox et al. 2015). The model shows how each of the variables that contributes to the decision to drink-or not to drink-is channeled through a motivational pathway to the final decision about whether to have a drink of alcohol on a particular occasion or not to have it. Some of the variables that contribute to the decision are proximal to it; other variables are more distal. The most proximal determinant of the decision is the net change in affect (enhancement of positive affect or reduction in negative affect, or both) that the person expects from drinking alcohol compared to not drinking it. Affective change is a central motivational concept because a desirable change in affect from its present state is the very essence of what people are motivated to achieve. Finally, it should be emphasized that the motivational model is a decisional model. That is, the decision to drink or not to drink is under the person's volitional control; nevertheless, the person might be unaware of some of the factors that affect the decision. 


\subsection{Distal determinants of drinking: past drinking experiences}

The kinds of experiences that people have previously had with drinking alcohol (i.e. the extent to which these experiences have been positive or negative) help to shape people's current expectations of affective changes from drinking and hence the value that they attribute to drinking alcohol. The nature of these experiences is largely determined by (1) each person's constitutional predisposition and (2) the environmental influences that affect drinking decisions.

One factor that will have affected the value of drinking alcohol is the alcohol flush reaction (Dickson et al. 2006). It includes unpleasant reactions, such as body flushes and nausea, which occur in people with a genetically determined deficiency in aldehyde dehydrogenase. Aldehyde dehydrogenase is the enzyme that normally metabolizes acetaldehyde, a toxic metabolite of alcohol, but acetaldehyde accumulates when people with a deficit in the enzyme consume alcohol. The flush reaction is common among people of Asian ancestry, but it might also occur among others. People with the reaction experience drinking alcohol as less pleasurable than other people do, and they have lower drinking rates.

Broad sociocultural influences are another kind of determinant of the value that different individuals place on drinking alcohol. For instance, it is commonly known that Italians are taught from an early age to drink in moderation, and social strictures are placed on drinking to excess. This pattern of moderate drinking can be seen today among Italian young people. For instance, university students in Italy have very low rates of heavy episodic drinking, and similar low rates are seen among university students in France, Germany, Greece, and some of the Eastern European countries (viz., Bulgaria, Hungary, and Romania; Dantzer et al. 2006). By contrast, university students in other European countries (viz. Belgium, Ireland, Poland, Netherlands, Slovakia) and in North America (e.g. United States) and South America (e.g. Columbia) have high rates of heavy episodic drinking (Dantzer et al. 2006). From a motivational perspective, these cultural influences can be explained in terms of how they affect the value that individuals attribute to drinking alcohol. That is, the value of drinking will increase to the extent that individuals model their own drinking behavior after that of other people around and are subtly or overtly reinforced for doing so.

Additionally, macroenvironmental influences, such as taxation and advertising, also affect the value that individuals place on drinking alcohol. Specifically, taxes on alcohol make drinking less attractive, whereas advertising alcohol makes it more attractive. In fact, it has been demonstrated that tax increases on alcohol and bans on advertising alcohol could bring about dramatic declines in alcohol-related deaths (Hollingworth et al. 2006).

Finally, it should be noted that substantial evidence has been gathered to demonstrate that people's motivation to drink alcohol-and hence the value that they attribute to drinking -is related to their personality characteristics. Some personality characteristics seem to protect people from drinking excessively; others seem to place them at risk for 
excessive drinking. Two personality characteristics have been commonly observed among heavy drinkers that appear to contribute to problematic drinking. They are (1) behavioral disinhibition in its various manifestations (e.g. impulsivity, reward dependence, sensation seeking), and (2) negative emotionality (e.g. hopelessness, anxiety sensitivity). People who are high in behavioral disinhibition value alcohol because of its rewarding properties; those who are high in negative emotionality value it because it helps to alleviate their dysphoria.

Generalizations about behavioral disinhibition and the misuse of alcohol are, however, somewhat tempered by recent results regarding the relationship between personality and substance dependence. Vrieze et al. (2014) studied this relationship by testing a large sample of twins longitudinally at ages 17,24 , and 29 . They found that the relationship between the personality characteristic constraint and substance dependence was small and largely genetic, with the genetic component declining from adolescence to adulthood. However, the relationship appears to have been mediated by traditionalism - the tendency to adhere to traditional moral and social values-rather than directly attributable to behavioral disinhibition.

\subsection{Current factors}

Certain current factors, i.e. factors that have an impact at the present time, might alter people's expectations about the positive or negative effects that drinking alcohol will have on their affect.

One such current factor is the immediate environmental context in which a person is located when he or she decides whether or not to imbibe. The environment affects, for instance, the person's perception of how available alcohol is and the extent to which drinking alcohol is approved in a particular situation (Huckle et al. 2008; Paschall et al. 2014). If a person perceives that alcohol is readily available and that drinking it is condoned, the affective benefits that the person expects to derive from drinking will be enhanced.

If alcohol is present, habitual drinkers might also have classically conditioned or other learned responses to alcohol and the stimuli associated with it, and these responses might intensify the person's anticipation of valued changes in affect resulting from drinking (see Field and Cox 2008; Field et al. 2009). At the same time, however, it should be noted that various applications of classical conditioning theory (including withdrawal, appetitive, incentive motivation, and classical operant models) which aim to understand alcohol cue reactivity have not been well supported in empirical investigations (Drobes et al. 2001). Alternative cognitive models to account for cue-reactivity phenomena seem to fare better.

\subsubsection{Incentive comparison effects}

As discussed, the motivational model of alcohol use predicts that people will be motivated to use alcohol or another addictive substance to the extent that they anticipate that doing so will result in desirable effects that they want to achieve. Using an addictive substance becomes an especially attractive way in which people can regulate their affect when they are unable to do so by other means. For example, when drinkers are feeling anxious or depressed, drinking alcohol is likely to temporarily alleviate their feelings of distress, and 
they are likely to turn to alcohol in order to cope with their negative feelings (Abrams et al. 2002; Ham et al. 2007; Hussong et al. 2001; Swendsen et al. 2000).

Similarly, people who have been treated for an alcohol-use disorder are more likely to relapse if their life situation is stressful and they do not have meaningful incentives to replace the alcohol (Moos et al. 1990; Zywiak et al. 2006a, 2006b); conversely, if these resources are available to them (Moos and Moos 2007) or they are actively engaged in problem solving (Demirbas et al. 2012), they are more likely to remain in remission. In fact, resolutions of drinking problems might occur without treatment if drinkers allocate their resources to achieving long-term goals rather than to drinking alcohol (Tucker et al. 2006, 2009).

Delayed reward discounting (which is common among people with a substance-use disorder and an index of their impulsivity; Amlung and MacKillop 2014; MacKillop et al. 2010) is one reason why incentives that could potentially serve as alternatives to drinking alcohol might not be attractive to people with an alcohol-use disorder. That is, these people more than others tend to discount the value of incentives that might bring them long-term but not short-term satisfaction. They prefer instead to obtain immediate mood-altering effects from drinking alcohol or using other drugs.

As alcohol and other substance users rely more and more on the substance as a way to regulate their affect, the attractiveness of other incentives erodes. In fact, the increasing value that substance users attribute to their substance and the concurrent loss in value of other incentives is reflected in the criteria that are used to define a substance use disorder. These include: "spending a lot of time getting, using, or recovering from use of the substance"; "not managing to do what you should at work, home or school, because of substance use"; "continuing to use, even when it causes problems in relationships"; "giving up important social, occupational or recreational activities because of substance use"; "using substances again and again, even when it puts you in danger"; "continuing to use, even when you know you have a physical or psychological problem that could have been caused or made worse by the substance" (American Psychiatric Association 2013). In other words, the incentive value of drinking alcohol or using another substance becomes greater than any other incentive available to the person. Kalivas and Volkow (2005) have concluded that this process is reflected physiologically in the brain as adaptation in prefrontal cells that innervate the nucleus accumbens, which results in a decrease in the value of natural rewards, reduced cognitive control, and increased sensitivity to substance-related stimuli.

Using functional magnetic resonance imaging (fMRI), Ihssen et al. (2011) assessed the relative value of alcohol and alternative incentives among preclinical participants. Specifically, they compared heavy drinkers' (alcohol consumption $=$ mean of $58.6 \mathrm{UK}$ units per week; one unit $=8$ grams of ethanol) and light drinkers' (alcohol consumption $=$ mean of $4.5 \mathrm{UK}$ units per week) brain reactions to various categories of pictorial stimuli, including pictures that were alcohol-related and those that were related to participants' higher-order goals. When presented with the alcohol-related pictures, the heavy drinkers had stronger reactions than the light drinkers in basic emotional areas of the insular cortex and in the reward circuitry of the ventral striatum. When presented with the pictures related to higher-order goals, the heavy drinkers responded more weakly 
than the light drinkers in the frontal areas of brain. Similarly, Garavan et al. (2000) used $f M R I$ to study cocaine users' and comparison participants' brain reactions to films depicting individuals smoking crack cocaine and to films with explicit sexual content. In the cocaine users, the cocaine cues activated similar brain areas as the evocative stimuli, but the cocaine users had a weaker brain response to the explicitly sexual stimuli than the comparison participants. The results confirm that overvaluation of alcohol or another addictive substance and undervaluation of alternative incentives is already reflected in the brain physiology of preclinical substance users.

\subsection{Cognitive mediators}

Based on their past and current experiences, people might come to value drinking alcohol or using another substance, and they might also expect that the valued consequences of using the substance will occur if they use it. In this case, the person will have formed a goal of procuring and using the substance, and the resulting current concern about using will be reflected in each person's cognitive processes. These will include memories of experiences about using the substance in the past; perceptions about the effects of using the substance (arising especially from environmental and sociocultural influences); thoughts about what will happen if the person uses; and attentional processes, such as taking notice of stimuli related to the substance in the environment. These processes, in turn, help to solidify each person's intention about whether or not to use.

Even though some of the cognitive mediators are unconscious, they can still have a strong influence on people's decision about whether or not to use. One of the variables that operates largely or entirely unconsciously is alcohol attentional bias. When people who have a concern about drinking alcohol encounter stimuli that are related to alcohol, they selectively attend to these stimuli while simultaneously filtering out stimuli that are not related to alcohol; in other words, they have an alcohol-related attentional bias. Research suggests that selective attention to alcohol fuels the motivation to drink, and it might result in actual drinking. In fact, the magnitude of the attentional bias, as measured with laboratory tasks, has been found to be positively associated with the amount of alcohol that drinkers habitually consume (see Cox et al. 2006, 2014, 2015).

The research on alcohol attentional bias and other implicit cognitive processes is presented next. The discussion describes both (1) how implicit cognitive processes are measured and (2) interventions that have been developed to overcome them.

\subsection{Importance of substance-related cognitive biases}

A substance-related cognitive bias is a bias in attention, thoughts, memories, interpretations, values (i.e. likes and dislikes), or action tendencies related to procuring or using an addictive substance. As discussed earlier, a cognitive bias normally is implicit and automatic; covertly, it might contribute to decision-making, behavioral tendencies, or action plans. Accordingly, in various ways substance-related cognitive biases play an important role in the continuation of and relapsing to addictive behaviors (Garland et al. 2012; Marhe et al. 2013). First, in the case of addiction to alcohol, cognitive biases can cause a 
drinker to be more aware of drinking-related cues in the environment. Second, they can interfere with the natural flow of a drinker's higher-order cognitive processes, including concentration (Waters and Green 2003) and working memory (Houston et al. 2014; Narendran et al. 2014; Wilcox et al. 2014). Third, they can change the natural flow of information processing in mesolimbic brain areas, such as the nucleus accumbens and the amygdala (Wiers, Stelzel, Park et al. 2014). Changes in these brain mechanisms might reduce the controlling role of reflective (cold) processes over impulsive (hot) processes and hence lead to less controlled patterns of substance use (Pieters et al. 2014; Smith et al. 2014). When executive cognitive functions that are responsible for reflective processes are impaired due to the adverse effects of chemical use (Fernandez-Serrano et al. 2010), the triggering effects of cognitive biases on drinking-related decisions can be exacerbated (Field et al. 2010; Loeber et al. 2009; Wiers, Stelzel, Gladwin et al. 2015). A cognitive bias, therefore, can lead a substance user to make decisions in favour of drug use despite the person's conscious vows to refrain from the use.

\section{Forms of cognitive bias}

Attentional bias. Selective attention or attentional bias refers to a person's tendency to focus on and give processing priority to stimuli that are related to his or her current concerns. Attentional bias for substance-related stimuli has been widely studied (Coskunpinar and Cyders 2013; Cox et al. 2006; Field and Cox 2008; Honsi et al. 2013; Leeman et al. 2014). According to the motivational model of alcohol abuse, the saliency of substance-related stimuli occurs because of the relevance of the stimulus to the person's present or previous current concerns (e.g. Cox and Klinger 2011a). Attentional bias affects one's perception of substance-related cues and hence one's motivation to use an addictive substance (Field and Cox 2008) because they grab and hold the person's attention to substance-related cues even when substance-unrelated cues are also present.

Most studies of attentional bias have used computer technology. A modified version of the classic Stroop test, the addiction Stroop test (Cox et al. 2006), has been widely used to study attentional bias among substance users and abusers. The test usually consists of two lists of words that have been lexically matched (e.g. on number of letters, frequency of usage, number of syllables), and each word is presented on a computer screen usually in one of four colors. One list is substance-related (i.e. the salient category) and the other list is substance-unrelated (i.e. the neutral category). The task for the participant is to ignore the meaning of each word and to respond as quickly and accurately as possible to the color of the font. Interference, which is a measure of the degree of the attentional bias for the substance-related stimuli, is calculated by subtracting each participant's mean reaction time to the neutral category from the mean reaction time to the salient category. In general, the magnitude of the interference is proportional to the degree of the substance use (Cox et al. 2006). In a recent review, Smith and Ersche (2014) concluded that the addiction Stroop test has diagnostic potential for differentiating between recreational and addicted drug users and for predicting treatment outcome. 
Another computerized test for measuring substance-related attentional bias is based on the probe-detection paradigm, the most frequently used form of which is the (visual/ pictorial) dot-probe task (Lubman et al. 2000). In its simplest form, the test normally consists of three consecutive screens: a fixation cross "+" briefly appears at the center of the screen; a pair of pictures (one salient and one control) then briefly appears side-byside or vertically but apart from each other; finally, a dot replaces the position of one of the pictures on the previous trial. The task for the participant is to respond to the position of the dot as quickly as possible by pressing one of the assigned keys (e.g. right or left arrow key). The rationale for the test is that the time spent in locating the dot when it replaces each control picture will be longer than when it replaces the salient stimuli, if the person has an attentional bias for the salient stimuli. The presentation time for the visual stimuli can be either short (e.g. $200 \mathrm{~ms}$ ) or long $(2000 \mathrm{~ms})$. Attentional bias observed at shorter vsersus longer presentation times can indicate whether any attentional bias that is observed occurs because the salient stimuli have captured the participant's attention at an early stage or whether it is because the person's attention to the salient stimuli is being maintained (Field et al. 2004). Although there have been many studies using the addiction Stroop test and visual-probe task that have found attentional bias for substance-related stimuli (Field and Cox 2008), some studies have failed to observe the attentional bias using these tests, probably because of procedural considerations or the target group that was tested (i.e. social/recreational users versus addicted users) (e.g. Marks et al. 2014).

Various other methods use computer technology to detect attentional bias for substancerelated stimuli: for example, the flicker change blindness paradigm, in which two images alternate, has been used (Jones et al. 2006). The two images are identical except for a minor change between them, which the participant is required to detect. People have been found to detect a change more readily when it is related to one of their current concerns (e.g. drinking alcohol) than when it is unrelated to their current concerns (Field et al. 2007; Jones et al. 2002, 2006).

Eye-tracking has been also used to study substance-related attentional bias, largely with smokers (Baschnagel 2013; Kang et al. 2012; Kwak et al. 2007; Van Rensburg et al. 2009) and drinkers (Rose et al. 2013), but mainly in combination with other techniques, such as the visual probe task (Marks et al. 2014) or the flicker paradigm (Hobson et al. 2013). In one study, Baschnagel (2013) used mobile eye-tracking to study smokers' attentional bias for smoking-related cues in the real world. The results of these studies show that attentional bias can be reliably detected via longer fixation times on the salient cues due to initial orienting of attention, especially when participants' craving is strong. However, among social/recreational users, the eye-tracking studies indicate initial orientation toward the salient stimuli (but not disengagement of attention from them). The studies, however, have reported that attentional bias does not fully mediate the relationship between cue reactivity and actual use of a substance (Rose et al. 2013). The limited use of eye-tracking in research on substance-related attentional bias warrants further studies, especially ones with addicted users. 


\subsection{Interpretation bias}

The word shot might remind some people of a gun firing, but for others it elicits cognitive processes and associations that are related to the act of drinking alcohol. Such associations are normally covert and automatic or implicit. In two recent studies (Woud et al. 2012, 2014), a novel task was used that included ambiguous open-ended scenarios. The task for the participants was to continue with the scenarios and complete them. They found that heavy drinkers showed greater interpretation bias for drinking alcohol than social drinkers did, and dependent drinkers showed greater interpretation bias than participants who were clinically diagnosed with an anxiety or depression disorder. Moreover, the degree of interpretation bias was positively associated with the problem drinkers' level of harmful drinking.

\subsection{Value bias}

As discussed earlier, current concerns reflect affective evaluations of goals, i.e. the value attributed to a goal, or how much joy, sadness, or sorrow is associated with it (Klinger and Cox 2011a). Although one can usually identify reasons for wanting to achieve a particular goal, some aspects of a goal's value are related to S-R conditioning (i.e. evaluative conditioning; EC) or some variant of it (Kosinski et al. 2015) that involves pairing a neutral stimulus with a positive or negative stimulus (De Houwer et al. 2001; Hofmann et al. 2010), which may occur at a conscious or a nonconscious level. Despite the emphasis that some researchers have placed on contingency awareness in EC (e.g. Field 2000), a recent meta-analysis by Hofmann et al. (2010) concluded that even low contingency awareness and subliminal presentation of the unconditioned stimulus can lead to evaluative conditioning of a CS. The value attributed to a goal may, therefore, be learned in both overt and covert ways, and it can affect one's goal-setting and goal pursuits without the person's being aware of it. It is not always easy to identify the reasons for our affective associations, but when they are strong enough they might distort our memories (Kensinger and Schacter 2005). To conclude, a goal that a person highly values is more likely to be chosen to pursue, even though the person might not know the reasons for the goal's desirability; likewise, something might be assiduously avoided despite the fact the person has no clue about the reasons for his or her distaste.

\subsection{Approach-avoidance bias}

There is a subtle interaction between people's movements and their tendency to approach or avoid something. Naturally, people prefer to approach things that they want and to avoid things that they do not want; this is termed executed movement (Neumann and Strack 2000). Even when we are not responsible for executing a movement, patterns of an object's motion in space are linked to our emotional evaluations of the object. For example, it is easier to positively evaluate neutral objects that approach us or move in waves on a horizontal line (i.e. ) than those that move smoothly (i.e. ---) along a horizontal line; likewise, objects that follow a parabolic (i.e. falling) pattern of motion can acquire 
negative valence (Kosinski et al. 2015). Such subtle influences on our evaluative learning, along with our past incentive history, determine our natural tendency to approach some objects and to avoid others. Likewise, when trying to resolve a concern, a person might want to approach a goal related to it (i.e. an appetitive goal) or to get rid of it (i.e. an aversive goal) (Klinger and Cox 2011a). Goal expectancies may also affect people's tendency to approach or avoid something related to the goal. Christiansen et al. (2013) reported that having positive alcohol expectancies can predict approach tendencies (e.g. to have a drink). This executed movement tendency gradually acquires an automatic quality. Evidence (Cousijn et al. 2011; Wiers, et al. 2013) shows that an automatic approach-bias for addiction-related cues can contribute to the continuation of the addictive behavior.

It is evident that addicted individuals have deficits in their general cognitive performance or executive functions (Field et al. 2010). Fadardi and Cox (2006) showed, however, that attentional bias for alcohol-related stimuli is not an artifact of drinkers' reduced executive functions; nevertheless, the strength of addicted individuals' executive functions is negatively related to their cognitive bias for substance-related stimuli. Loeber et al. (2009) found that attentional bias for alcohol-related stimuli was modulated by drinkers' executive functions (i.e. attention and working memory), and other studies (Christiansen et al. 2012; Friese et al. 2010; Smith et al. 2014) have also shown that executive function deficits can increase abusers' impulsive decisions to consume substances. In short, these studies suggest that it would be important to help substance abusers to increase their general self-control in order for them to be better able to control their substance use.

\section{Enhancing self-control}

Enhancing drinkers' self-control has long been a goal in the treatment of addictive behaviors (Marlatt 1982; Marlatt and Marques 1977; Room and Leigh 1992). Motivational approaches, such as motivational interviewing (Rubak et al. 2005), employ techniques to persuade substance users to progress through stages of change (i.e. pre-contemplation, contemplation, action, and maintenance). Systematic motivational counseling (Cox and Klinger 2011b) uses techniques to improve substance users' lifestyle to help them disengage from substance use while they are achieving more fulfilling, substance-unrelated goals. Shamloo and Cox (2014) showed that (1) providing participants with hints about how to complete two experimental tasks and (2) giving them contingent, immediate feedback about their performance in completing individualized goals led to an increase in participants' sense of control and adaptive motivation and to decreases in explicit and implicit measures of their urge to drink alcohol. This is an interesting finding because none of the tasks were directly related to drinking alcohol. Fadardi and colleagues (2011) discussed the reciprocal nature of motivational and cognitive determinants of substance abuse and how improvements in one of these determinants can bring improvements in the other. In fact, sense of control is an important predictor of treatment outcomes in many kinds of interventions for substance abuse, including medical interventions, cognitive behavioral therapy, contingency management, mindfulness training, and cognitive bias modification (Leeman et al. 2014). 


\section{Cognitive bias modification}

Theoretically driven and rationally based on the results of studies on different kinds of cognitive bias in substance-use disorders, various kinds of cognitive bias modification (CBM) have been developed, and their effectiveness in reducing substance-related cognitive biases and improvement of treatment outcomes has been evaluated. There are various kinds of CBM: CBM-A refers to modification in attentional bias (e.g. Begh et al. 2013; Fadardi and Cox 2009; Wiers, Houben et al. 2015); CBM-I refers to techniques for changing interpretation biases related to substance-related stimuli; and CBM-V refers to techniques for reducing positive evaluations of substance-related stimuli or situations and the act of using the substance. On the other hand, approach-bias modification involves reducing automatic tendencies to approach and obtain a substance (Eberl et al. 2013, 2014; Sharbanee et al. 2014; Wiers, Stelzel, Gladwin et al. 2015). Although a single session of CBM usually does not lead to reductions in attentional bias or craving and does not help to prevent relapse (Field et al. 2009), interventions with multiple training sessions have led to positive clinical outcomes (see Cox et al. 2015).

Most of the CBM techniques aim to strengthen substance users' inhibitory ability when they encounter substance-related stimuli in order to (1) prevent allocation of their attention at an early stage of cognitive processing (i.e. while initially perceiving a stimulus) or (2) disengage their attention at a later stage. These techniques instead promote cognitive allocation to alternative neutral or even positive stimuli. Such a shift requires conscious effort and frequent rehearsal, usually using a computerized program. Normally, the training procedure includes providing the trainee with a hierarchy of goals to reach through increasingly difficult steps. The program covertly (e.g. in modified versions of the dotprobe task or in CBM-I or CBM-V techniques) or overtly (e.g. in modified versions of the Stroop task, such as the Alcohol Attention Control Training Program (AACTP), Fadardi and Cox 2009) reinforces controlled ways of responding to target stimuli or situations. Thereby, the person gradually learns one of several things: (1) to ignore substance-related stimuli (e.g. alcohol-related items in the environment) and simultaneously attend to non-alcohol-related stimuli; (2) to interpret in a more positive, healthier, and substanceunrelated way situations that have been habitually associated with alcohol or another substance; (3) to reduce the positive emotional valence associated with the act of drinking alcohol or using another substance and substance-related situations; or (4) to reject alcohol or other substances when they are presented. As indicated, practice with these programs both reduces the substance user's cognitive bias and enhances his or her sense of control over a previously habitual behavior, thereby further enhancing the motivation to control the substance use.

Cox and colleagues (2015) evaluated whether combining systematic motivational counseling and attentional training using the AACTP could have additive effects in helping addicted drinkers reduce the amount of alcohol that they habitually drank. The study used a $2 \times 2$ factorial design, and outcome was measured post-intervention and then three and six months later. Results showed that there was no additive effect for combining the 
two interventions. However, the attentional retraining rapidly reduced heavy drinkers' mean weekly drinking but the effects did not endure. The motivational intervention was effective at reducing weekly drinking; however, the effect appeared after some delay but lasted longer than the effects of the attentional training. Clearly, more research is needed to study the temporal course and additive effects of behavioral, CBM, and motivational interventions for substance use and relapse prevention.

\section{Summary}

This chapter presents a view of addiction from the standpoint of the motivational and goal theory of current concerns. A current concern is an individual's motivational state between becoming committed to pursuing a particular goal and the point at which the goal is reached or the pursuit is relinquished. During this time, the current concern guides the person's cognitive processes, including attention, memories, thoughts, and dreams. What is true of goals in general is true of the goal of drinking alcohol or using another addictive substance. Whether or not a person decides to drink alcohol or use an addictive substance will depend on the value that the person attributes to drinking or using (i.e. the expected enhancement of positive affect or reduction in negative affect) and the person's expectation that the expected changes in affect will actually happen. Many factors help to determine the value that the person attributes to drinking, such as his or her past drinking experiences, biochemical reactions to alcohol, environmental and sociocultural influences, and the incentives in the person's life that might compete with trying to obtain emotional satisfaction from drinking or using an addictive substance. When a goal to drink or use is formed, the goal is reflected in the person's cognitive processes (e.g. thoughts, memories, and attention). These cognitive processes facilitate obtaining and imbibing the addictive substance. Accordingly, interventions can help the person to counteract these processes and reduce his or her use of substances. This chapter has presented several of these interventions and the research that has been conducted to evaluate them.

\section{Acknowledgments}

The work described in this chapter was supported by Economic and Social Research Council Grant RES-000-23-9563 (awarded to W. Miles Cox and Emmanuel M. Pothos), Economic and Social Research Council Grant RES-000-22-0314 (awarded to W. Miles Cox and Javad Salehi Fadardi), and Economic and Social Research Council Grant RES000-23-1269 (awarded to W. Miles Cox, Javad S. Fadardi, Steven G. Hosier, and Emmanuel M. Pothos).

\section{References}

Abrams, K., Kushner, M.G., Medina, K.L., and Voight, A. (2002). Self-administration of alcohol before and after a public speaking challenge by individuals with social phobia. Psychology of Addictive Behaviors, 16, 121-8.

Aldao, A., Nolen-Hoeksema, S., and Schweizer, S. (2010). Emotion-regulation strategies across psychopathology: A meta-analytic review. Clinical Psychology Review, 30, 217-37. 
American Psychiatric Association. (2013). Diagnostic and Statistical Manual of Mental Disorders (5th ed.). Washington, DC: APA.

Amlung, M. and MacKillop, J. (2014). Clarifying the relationship between impulsive delay discounting and nicotine dependence. Psychology of Addictive Behaviors, 28, 761-68.

Baschnagel, J.S. (2013). Using mobile eye-tracking to assess attention to smoking cues in a naturalized environment. Addictive Behaviors, 38, 2837-40. DOI: 10.1016/j.addbeh.2013.08.005

Begh, R., Munafo, M.R., Shiffman, S., et al. (2013). Attentional bias retraining in cigarette smokers attempting smoking cessation (ARTS): study protocol for a double blind randomised controlled trial. BMC Public Health, 13, 1176. DOI: 10.1186/1471-2458-13-1176

Berkman, E.T. and Lieberman, M.D. (2009). The neuroscience of goal pursuit: Bridging gaps between theory and data. In: G.B. Moskowitz and H. Grant (eds), The Psychology of Goals. New York: Guilford, pp. 98-126.

Berridge K.C. (2007). The debate over dopamine's role in reward: the case for incentive salience. Psychopharmacology, 191, 391-431.

Bischof, G., Rumph, H.-J., and John, U. (2012). Natural recovery from addiction. In: H. Shaffer, D.A. LaPlante, and S.E. Nelson (eds), APA Addiction Syndrome Handbook, Vol. 2: Recovery, Prevention, and Other Issues Washington, DC: APA, pp. 133-55.

Bock, M. and Klinger, E. (1986). Interaction of emotion and cognition in word recall. Psychological Research, 48, 99-106

Bouton, M.E. (2002). Context, ambiguity, and unlearning: Ssources of relapse after behavioral extinction. Biological Psychiatry, 52, 976-86.

Brandstätter, V., Herrmann, M., and Schüler, J. (2013). The struggle of giving up personal goals: affective, physiological, and cognitive consequences of an action crisis. Personality and Social Psychology Bulletin, 39, 1668-82.

Bundorf, M.K., Mata, R., Schoenbaum, M., and Bhattacharya, J. (2013). Are prescription drug insurance choices consistent with expected utility theory? Health Psychology, 32, 986-94.

Carver, C.S., and Scheier, M.F. (1998). On the Self-Regulation of Behavior. New York: Cambridge University Press.

Cesario, J. (2014). Priming, replication, and the hardest science. Perspectives on Psychological Science, 9, 40-48.

Chartrand, T.L. and Bargh, J.A. (1996). Automatic activation of impression formation and memorization goals: Nonconscious goal priming reproduces effects of explicit task instructions. Journal of Personality and Social Psychology, 71, 464-78.

Christiansen, P., Cole, J.C., and Field, M. (2012). Ego depletion increases ad-lib alcohol consumption: investigating cognitive mediators and moderators. Exprimental and Clinical Psychopharmacology, 20, 118-28. DOI: $10.1037 / \mathrm{a} 0026623$

Christiansen, P., Rose, A.K., Cole, J.C., and Field, M. (2013). A comparison of the anticipated and pharmacological effects of alcohol on cognitive bias, executive function, craving and ad-lib drinking. Journal of Psychopharmacol, 27, 84-92. DOI: 10.1177/0269881112450787

Coskunpinar, A., and Cyders, M.A. (2013). Impulsivity and substance-related attentional bias: a meta-analytic review. Drug and Alcohol Dependence, 133,1-14. DOI: 10.1016/ j.drugalcdep.2013.05.008

Cousijn, J., Goudriaan, A.E., and Wiers, R.W. (2011). Reaching out towards cannabis: approach-bias in heavy cannabis users predicts changes in cannabis use. Addiction, 106, 1667-74. DOI: 10.1111/ j.1360-0443.2011.03475.x

Cox, W.M. and Klinger, E. (1988). A motivational model of alcohol use. Journal of Abnormal Psychology, 97, 168-80.

Cox, W.M. and Klinger, E. (2011a). A motivational model of alcohol use: determinants of use and change. In: W.M. Cox and E. Klinger (eds), Handbook of Motivational Counseling: Goal-Based 
Approaches to Assessment and Intervention with Addiction and Other Problems. Chichester: WileyBlackwell, pp. 131-58.

Cox, W.M. and Klinger, E. (2011b). Systematic motivational counseling: from motivational assessment to motivational change. In: W.M. Cox and E. Klinger (eds), Handbook of Motivational Counseling: Goal-Based Approaches to Assessment and Intervention with Addiction and Other Problems. Chichester, UK: Wiley-Blackwell, pp. 275-302.

Cox, W.M., Fadardi, J.S., and Pothos, E.M. (2006). The addiction-Stroop test: theoretical considerations and procedural recommendations. Psychological Bulletin, 132, 443-76. DOI: 2006-06233-005 [pii]10.1037/0033-2909.132.3.443

Cox, W.M., Klinger, E., and Fadardi, J.S. (2015). The motivational basis of cognitive determinants of addictive behaviors. Addictive Behaviors, 44, 16-22.

Cox, W. M., Fadardi, J. S., Hosier, S. G., and Pothos, E. M. (2015). Differential effects and temporal course of attentional and motivational training on excessive drinking. Experimental and Clinical Psychopharmacology, 23(6), 445-454.

Cox, W.M., Fadardi, J.S., Hosier, S.G., and Pothos, E.M. (2015). Differential effects and temporal course of attentional and motivational training on excessive drinking. Experimental and Clinical Psychopharmacology, 23(6), 445-54.

Cox, W.M., Schippers, G.M., Klinger, E., et al. (2002). Motivational structure and alcohol use of university students with consistency across four nations. Journal of Studies on Alcohol, 63, 280-85.

Dantzer, C., Wardle, J., Fuller, R., Pampalone, S.Z., and Steptoe, A. (2006). International study of heavy drinking: attitudes and sociodemographic factors in university students. Journal of American College Health, 55, 83-89.

De Houwer, J., Thomas, S., and Baeyens, F. (2001). Associative learning of likes and dislikes: a review of 25 years of research on human evaluative conditioning. Psychological Bulletin, 127, 853-69.

Demirbas, H., Ilhan, I.O., and Dogan, Y.B. (2012). Ways of problem solving as predictors of relapse in alcohol dependent male inpatients. Addictive Behaviors, 37, 131-4.

Dickson, P., A. James, M.R., Heath, A.C. et al. (2006). Effects of variation at the ALDH2 locus on alcohol metabolism, sensitivity, consumption, and dependence in Europeans. Alcoholism: Clinical and Experimental Research, 30, 1093-100.

Drobes, D.J., Saladin, M.E., and Tiffany, S.T. (2001). Classical conditioning mechanisms in alcohol dependence. In: N. Heather, T.J. Peters, and T. Stockwell (eds), International Handbook of Alcohol Dependence and Problems. Chichester, UK: John Wiley, pp. 281-97).

Eberl, C., Wiers, R.W., Pawelczack, S., Rinck, M., Becker, E.S., and Lindenmeyer, J. (2013). Approach bias modification in alcohol dependence: do clinical effects replicate and for whom does it work best? Developmental Cognitive Neuroscience, 4, 38-51. DOI: 10.1016/j.dcn.2012.11.002

Eberl, C., Wiers, R.W., Pawelczack, S., Rinck, M., Becker, E.S., and Lindenmeyer, J. (2014). Implementation of approach bias re-training in alcoholism-how many sessions are needed? Alcoholism: Clinical and Experimental Research, 38, 587-94. DOI: 10.1111/acer.12281

Fadardi, J.S. and Cox, W.M. (2006). Alcohol attentional bias: drinking salience or cognitive impairment? Psychopharmacology, 185, 169-78. DOI: DOI:10.1007/s00213-005-0268-0

Fadardi, J.S. and Cox, W.M. (2009). Reversing the sequence: reducing alcohol consumption by overcoming alcohol attentional bias. Drug and Alcohol Dependence, 101, 137-45. DOI: S03768716(08)00434-1 [pii]10.1016/j.drugalcdep.2008.11.015

Fadardi, J.S., Shamloo, Z.S., and Cox, W.M. (2011). Cognitive and motivational retraining: reciprocal effects. In W.M. Cox and E. Klinger (eds), Handbook of Motivational Counseling: Concepts, Approaches, and Assessment. Chichester: John Wiley, pp. 395-411. 
Feather, N.T. (ed.) (1982). Expectations and Actions: Expectancy-value Models in Psychology. Hillsdale, NJ: Erlbaum.

Feil, J., Sheppard, D., Fitzgerald, P.B., Yücel, M., Lubman, D.I., and Bradshaw, J.L. (2010). Addiction, compulsive drug seeking, and the role of frontostriatal mechanisms in regulating inhibitory control. Neuroscience and Biobehavioral Reviews, 35, 248-75.

Fernandez-Serrano, M.J., Perez-Garcia, M., Schmidt Rio-Valle, J., and Verdejo-Garcia, A. (2010). Neuropsychological consequences of alcohol and drug abuse on different components of executive functions. Journal of Psychopharmacology, 24, 1317-32. DOI: 10.1177/0269881109349841

Field, A.P. (2000). I like it, but I'm not sure why: can evaluative conditioning occur without conscious awareness? Consciousness and Cognition, 9, 13-36. DOI: 10.1006/ccog.1999.0402

Field, M. and Cox, W.M. (2008). Attentional bias in addictive behaviors: a model of its development, causes, and consequences. Drug and Alcohol Dependence, 97, 1-20.

Field, M., Munafo, M.R., and Franken, I.H.A. (2009). A meta-analytic investigation of the relationship between attentional bias and subjective craving in substance abuse. Psychological Bulletin, 135, 589-607.

Field, M., Duka, T., Tyler, E., and Schoenmakers, T. (2009). Attentional bias modification in tobacco smokers. Nicotine and Tobaco Research, 11, 812-22. DOI: ntp067 [pii]10.1093/ntr/ntp067

Field, M., Mogg, K., Zetteler, J., and Bradley, B.P. (2004). Attentional biases for alcohol cues in heavy and light social drinkers: the roles of initial orienting and maintained attention. Psychopharmacology (Berlin), 176, 88-93.

Field, M., Wiers, R.W., Christiansen, P., Fillmore, M.T., and Verster, J.C. (2010). Acute alcohol effects on inhibitory control and implicit cognition: implications for loss of control over drinking. Alcoholism: Clinical and Experimental Research, 34, 1346-52. DOI: 10.1111/ j.1530-0277.2010.01218.x

Field, M., Duka, T., Eastwood, B., Child, R., Santarcangelo, M., and Gayton, M. (2007). Experimental manipulation of attentional biases in heavy drinkers: do the effects generalise? Psychopharmacology (Berlin), 192, 593-608. DOI: 10.1007/s00213-007-0760-9

Foa, E.B., Liebowitz, M.R., Kozak, M.J., et al. (2005). Randomized, placebo-controlled trial of exposure and ritual prevention, clomipramine, and their combination in the treatment of obsessivecompulsive disorder. American Journal of Psychiatry, 162, 151-61.

Förster, J., Liberman, N., and Friedman, R.S. (2007). Seven principles of goal activation: A systematic approach to distinguishing goal priming from priming of non-goal constructs. Personality and Social Psychology Review, 11, 211-33.

Friese, M., Bargas-Avila, J., Hofmann, W., and Wiers, R.W. (2010). Here's looking at you, bud: alcohol-related memory structures predict eye movements for social drinkers with low executive control. Social Psychological and Personality Science, 1, 143-51. DOI: $10.1177 /$ 1948550609359945

Garavan, H., Pankiewicz, J., Bloom, A., et al. (2000). A cue-induced cocaine craving: neuroanatomical specificity for drug users and drug stimuli. American Journal of Psychiatry, 157, 1789-98.

Garland, E.L., Franken, I.H., and Howard, M.O. (2012). Cue-elicited heart rate variability and attentional bias predict alcohol relapse following treatment. Psychopharmacology (Berlin), 222, 1726. DOI: $10.1007 / \mathrm{s} 00213-011-2618-4$

Haaker, J., Golkar, A., Hermans, D., and Lonsdorf, T.B. (2014). A review on human reinstatement studies: An overview and methodological challenges. Learning and Memory, 21, 424-40.

Ham, L.S., Bonin, M., and Hope, D.A. (2007). The role of drinking motives in social anxiety and alcohol use. Journal of Anxiety Disorders, 21, 991-1003.

Heyman, G.M. (2009). Addiction: A Disorder of Choice. Cambridge, MA: Harvard University Press. 
Hobson, J., Bruce, G., and Butler, S.H. (2013). A flicker change blindness task employing eye tracking reveals an association with levels of craving not consumption. Journal of Psychopharmacology, 27, 93-97. DOI: $10.1177 / 0269881112447990$

Hoelscher, T.J., Klinger, E., and Barta, S.G. (1981). Incorporation of concern- and nonconcern-related verbal stimuli into dream content. Journal of Abnormal Psychology, 49, 88-91.

Hofmann, W., De Houwer, J., Perugini, M., Baeyens, F., and Crombez, G. (2010). Evaluative conditioning in humans: a meta-analysis. Psychological Bulletin, 136, 390-421. DOI:10.1037/ a0018916

Hollingworth, W., Ebel, B.E., McCarty, C.A., et al. (2006). Prevention of deaths from harmful drinking in the United States: The potential effects of tax increases and advertising bans on young drinkers. Journal of Studies on Alcohol, 67, 300-308.

Honsi, A., Mentzoni, R.A., Molde, H., and Pallesen, S. (2013). Attentional bias in problem gambling: a systematic review. Journal of Gambling Studies, 29, 359-75. DOI: 10.1007/s10899-012-9315-z

Houston, R.J., Derrick, J.L., Leonard, K.E., Testa, M., Quigley, B.M., and Kubiak, A. (2014). Effects of heavy drinking on executive cognitive functioning in a community sample. Addictive Behaviors, 39, $345-49$.

Huang, J.Y., and Bargh, J.A. (2014). The selfish goal: autonomously operating motivational structures as the proximate cause of human judgment and behavior. Behavioral and Brain Sciences, 37, 121-35.

Huckle, T., Huakau, J., Sweetsur, P., Huisman, O. and Casswell, S. (2008). Density of alcohol outlets and teenage drinking: living in an alcogenic environment is associated with higher consumption in a metropolitan setting. Addiction, 103, 1614-21.

Hussong, A.M., Hicks, R.E., Levy, S.A., and Curran, P.J. (2001). Specifying the relations between affect and heavy alcohol use among young adults. Journal of Abnormal Psychology, 110, 449-61.

Ihssen, N., Cox, W.M., Wiggett, A., Fadardi, J.S., and Linden, D.E. J. (2011). Heavy and light drinkers' brain reactions to alcohol, goal-related, emotional, and neutral stimuli. Cerebral Cortex, 21, 1408-15.

Jones, B.C., Jones, B.T., Blundell, L., and Bruce, G. (2002). Social users of alcohol and cannabis who detect substance-related changes in a change blindness paradigm report higher levels of use than those detecting substance-neutral changes. Psychopharmacology (Berlin), 165, 93-6. DOI:10.1007/ s00213-002-1264-2

Jones, B.T., Bruce, G., Livingstone, S., and Reed, E. (2006). Alcohol-related attentional bias in problem drinkers with the flicker change blindness paradigm. Psychology of Addictive Behaviors, 20, 171-7. DOI:10.1037/0893-164X.20.2.171

Kalivas, P.W. and Volkow, N.D. (2005). The neural basis of addiction: A pathology of motivation and choice. American Journal of Psychiatry, 162, 1403-13.

Kang, O.S., Chang, D.S., Jahng, G.H., et al. (2012). Individual differences in smoking-related cue reactivity in smokers: an eye-tracking and fMRI study. Progress in Neuropsychopharmacology and Biological Psychiatry, 38, 285-93. DOI: 10.1016/j.pnpbp.2012.04.013

Kensinger, E.A., and Schacter, D.L. (2005). Retrieving accurate and distorted memories: neuroimaging evidence for effects of emotion. Neuroimage, 27, 167-77. DOI: 10.1016/j.neuroimage.2005.03.038

Klingemann, H.K.-H. (2001). Natural recovery from alcohol problems. In: N. Heather, T.J. Peters, and T.R. Stockwell (eds), Handbook of Alcohol Dependence and Related Problems. New York: John Wiley, pp. 649-62.

Klinger, E. (1971). Structure and Functions of Fantasy. New York: John Wiley.

Klinger, E. (1975). Consequences of commitment to and disengagement from incentives. Psychological Review, 82, 1-25.

Klinger, E. (1977). Meaning and Void: Inner Experience and the Incentives in People's Lives. Minneapolis: University of Minnesota Press. 
Klinger, E. (1978). Modes of normal conscious flow. In: K.S. Pope and J.L. Singer (eds), The Stream of Consciousness: Scientific Investigations into the Flow of Human Experience. New York: Plenum, pp. 225-58.

Klinger, E. (1987). Current concerns and disengagement from incentives. In: F. Halisch and J. Kuhl (eds), Motivation, Intention and Volition. Berlin: Springer, pp. 337-47.

Klinger, E. (1990). Daydreaming. Los Angeles, CA: Tarcher (Putnam).

Klinger, E. (1993). Loss of interest. In: C.G. Costello (ed.), Symptoms of Depression. New York: Wiley, pp. 43-62.

Klinger, E. (1996a). Emotional influences on cognitive processing, with implications for theories of both. In: P. Gollwitzer and J.A. Bargh (eds), The Psychology of Action: Linking Cognition and Motivation to Behavior. New York: Guilford, pp. 168-89).

Klinger, E. (1996b). The contents of thoughts: interference as the downside of adaptive normal mechanisms in thought flow. In: I.G. Sarason, B.R. Sarason, and G.R. Pierce (eds), Cognitive interference: Theories, Methods, and Findings. Hillsdale, NJ: Lawrence Erlbaum Associates, pp. 3-23.

Klinger, E. (2012). The search for meaning in evolutionary perspective and its clinical implications. In: P.T.P. Wong (ed.), The Human Quest for Meaning: Theories, Research, and Applications (2nd ed.). New York: Routledge, pp. 23-56.

Klinger, E. (2013). Goal commitments and the content of thoughts and dreams: Basic principles. Frontiers in Psychology, 4, DOI: 10.3389/fpsyg.2013.00415.

Klinger, E. and Cox, W.M. (2011a). Motivation and the goal theory of current concerns. In: W.M. Cox and E. Klinger (eds), Handbook of Motivational Counseling (2nd ed.). Chichester, UK: WileyBlackwell, pp. 3-47.

Klinger, E. and Cox, W.M. (2011b). The Motivational Structure Questionnaire, Personal Concerns Inventory, and their variants: psychometric properties. In: W.M. Cox and E. Klinger (eds), Handbook of Motivational Counseling (2nd ed.). Chichester, UK: Wiley-Blackwell, pp. 205-32.

Klinger, E., and McNelly, F.W., Jr. (1969). Fantasy need achievement and performance: a role analysis. Psychological Review, 76, 574-91.

Klinger, E., Barta, S.G., and Maxeiner, M.E. (1980). Motivational correlates of thought content frequency and commitment. Journal of Personality and Social Psychology, 39, 1222-37.

Köhler W. (1925). The Mentality of Apes. New York: Harcourt, Brace.

Kosinski, T., Chafi, A., and Rusinek, S. (2015). When motion changes liking: evaluative conditioning with motion as unconditioned stimulus. Learning and Motivation, 49, 1-5. DOI: $10.1016 /$ j.Imot.2014.10.003

Koster, E.H. W., De Lissnyder, E., Derakshan, N., and De Raedt, R. (2011). Understanding depressive rumination from a cognitive science perspective: the impaired disengagement hypothesis. Clinical Psychology Review, 31, 138-45.

Kouneiher, F., Charron, S., and Koechlin, E. (2009). Motivation and cognitive control in the human prefrontal cortex. Nature Neuroscience, 12, 939-45.

Kwak, S.M., Na, D.L., Kim, G., Kim, G.S., and Lee, J.H. (2007). Use of eye movement to measure smokers' attentional bias to smoking-related cues. Cyberpsychology and Behavior, 10, 299-304. DOI: $10.1089 /$ cpb.2006.9953

Leeman, R.F., Bogart, D., Fucito, L.M., and Boettiger, C.A. (2014). "Killing two birds with one stone": alcohol use reduction interventions with potential efficacy in enhancing self-control. Current Addiction Reports, 1, 41-52. DOI: 10.1007/s40429-013-0008-1

Leeman, R.F., Robinson, C.D., Waters, A.J., and Sofuoglu, M. (2014). A critical review of the literature on attentional bias in cocaine use disorder and suggestions for future research. Experimental and Clinical Psychopharmacology, 22, 469-83. DOI: 10.1037/a0037806

Paschall, M.J., Lipperman-Kreda, S., and Grube, J.W. (2014). Effects of the local alcohol environment on adolescents' drinking behaviors and beliefs. Addiction, 109, 407-16. 
Loeber, S., Vollstadt-Klein, S., von der Goltz, C., Flor, H., Mann, K., and Kiefer, F. (2009). Attentional bias in alcohol-dependent patients: the role of chronicity and executive functioning. Addiction Biology, 14, 194-203. DOI: ADB146 [pii]10.1111/j.1369-1600.2009.00146.x

Lubman, D.I., Peters, L.A., Mogg, K., Bradley, B.P., and Deakin, J.F. (2000). Attentional bias for drug cues in opiate dependence. Psychological Medecine, 30, 169-75.

MacKillop, J., Miranda, R., Jr., Monti, P.M. et al. (2010). Alcohol demand, delayed reward discounting, and mediation by craving in individuals with alcohol use disorders. Journal of Abnormal Psychology, 119, 106-14.

Marchetti, I., Koster, E.H.W., and De Raedt, R. (2012a). Mindwandering heightens the accessibility of negative relative to positive thought. Consciousness and Cognition, 21, 1517-25.

Marchetti, I., Koster, E.H., Sonuga-Barke, E.J., and De Raedt, R. (2012b). The default mode network and recurrent depression: a neurobiological model of cognitive risk factors. Neuropsychology Review, 22, 229-51.

Marhe, R., Waters, A.J., van de Wetering, B.J., and Franken, I.H. (2013). Implicit and explicit drugrelated cognitions during detoxification treatment are associated with drug relapse: an ecological momentary assessment study. Journal of Consulting and Clinical Psychology, 81, 1-12. DOI:10.1037/ a0030754

Marien, H., Custers, R., Hassin, R.R., and Aarts, H. (2012). Unconscious goal activation and the hijacking of the executive function. Journal of Personality and Social Psychology, 103, 399-415.

Marks, K.R., Pike, E., Stoops, W.W., and Rush, C.R. (2014). Test-retest reliability of eye tracking during the visual probe task in cocaine-using adults. Drug and Alcohol Dependence, 145, 235-7. DOI: 10.1016/j.drugalcdep.2014.09.784

Marks, K.R., Roberts, W., Stoops, W.W., Pike, E., Fillmore, M.T., and Rush, C.R. (2014). Fixation time is a sensitive measure of cocaine cue attentional bias. Addiction, 109, 1501-8. DOI: 10.1111/ add. 12635

Marlatt, G.A. (1982). Relapse prevention: a self-control program for the treatment of addictive behaviors. In: R.B. Stuart (ed.), Adherence, Compliance and Generalization in Behavioral Medicine. New York: Brunner/Mazel, pp. 329-77.

Marlatt, G.A., and Marques, J.K. (1977). Meditation, self-control and alcohol use. In R.B. Stuart (ed.), Behavioral Self-management: Strategies, Techniques and Outcomes. New York: Brunner/Mazel, pp. 117-53.

McGeoch, J.A. (1993). Studies in retroactive inhibition: the temporal course of the inhibitory effects of interpolated learning. Journal of General Psychology, 9, 24-42.

Mongin, P. (1997). Expected utility theory. In J. Davis, W. Hands, \& U. Maki (Eds.), Handbook of economic methodology (pp. 342-350). London: Edward Elgar.

Montagrin, A., Brosch, T., and Sander, D. (2013). Goal conduciveness as a key determinant of memory facilitation. Emotion, 13, 622-28.

Moos, R.H. and Moos, B.S. (2007). Treated and untreated alcohol-use disorders: Course and predictors of remission and relapse. Evaluation Review, 31, 564-84.

Moos, R.H., Finney, J.W., and Cronkite, R.C. (1990). Alcoholism Treatment: Context, Process, and Outcome. New York: Oxford University Press.

Morone, A. and Morone, P. (2014). Estimating individual and group preference functionals using experimental data. Theory and Decision, DOI: http://dx.doi.org/10.1007/s11238-014-9431-6

Moskowitz, G.B.,] and Balcetis, E. (2014). The conscious roots of selfless, unconscious goals. Behavioral and Brain Sciences, 37, 151.

Moskowitz, G.B., Li, P., Ignarri, C., and Stone, J. (2011). Compensatory cognition associated with egalitarian goals. Journal of Experimental Social Psychology, 47, 365-70. 
Moss A.C. and Albery, I.P. (2009). A dual-process model of the alcohol-behavior link for social drinking. Psychological Bulletin, 135, 516-30.

Narendran, R., Mason, N.S., Paris, J., Himes, M.L., Douaihy, A.B., and Frankle, W.G. (2014). Decreased prefrontal cortical dopamine transmission in alcoholism. American Journal of Psychiatry, 171, 881-8. DOI:10.1176/appi.ajp.2014.13121581

Neumann, R. and Strack, F. (2000). Approach and avoidance: the influence of proprioceptive and exteroceptive cues on encoding of affective information. Journal of Personality and Social Psychology, 79, 39-48.

Nikles, C.D.II, Brecht, D.L., Klinger, E., and Bursell, A.L. (1998). The effects of current-concern- and nonconcern-related waking suggestions on nocturnal dream content. Journal of Personality and Social Psychology, 75, 242-55.

Nikula, R., Klinger, E., and Larson-Gutman, M.K. (1993). Current concerns and electrodermal reactivity: Responses to words and thoughts. Journal of Personality, 61, 63-84.

Noël, X., Bechara, A., Brevers, D., Verbanck, P., and Campanella, S. (2010). Alcoholism and the loss of willpower: A neurocognitive perspective. Journal of Psychophysiology, 24, 240-8.

Noël, X., Brevers, D., and Bechara, A. (2013). A triadic neurocognitive approach to addiction for clinical interventions. Frontiers in Psychiatry, 4 DOI:http://dx.doi.org/10.3389/fpsyt.2013.00179

Nolen-Hoeksema, S., Wisco, B.E., and Lyubomirsky, S. (2008). Rethinking rumination. Perspectives on Psychological Science, 3, 400-24.

Ostafin, B.D., Bauer, C., and Myxter, P. (2012). Mindfulness decouples the relation between automatic alcohol motivation and heavy drinking. Journal of Social and Clinical Psychology, 31, 729-45.

Paschall, M.J., Lipperman-Kreda, S., and Grube, J.W. (2014). Effects of the performance: a role analysis. Psychological Review, 76, 574-91.

Pieters, S., Burk, W.J., Van der Vorst, H., Engels, R.C., and Wiers, R.W. (2014). Impulsive and reflective processes related to alcohol use in young adolescents. Frontiers in Psychiatry, 5, 56. DOI: 10.3389/ fpsyt.2014.00056

Quinlan, S., Jaccard, J., and Blanton, H. (2006). A decision theoretic and prototype conceptualization of possible selves: Implications for the prediction of risk behavior. Journal of Personality, 74, $600-30$.

Room, R. and Leigh, B.C. (1992). Self-control concerns and drinking loss of control in general and clinical populations. Journal of Studies on Alcohol, 53, 590-93.

Rose, A.K., Brown, K., Field, M., and Hogarth, L. (2013). The contributions of value-based decisionmaking and attentional bias to alcohol-seeking following devaluation. Addiction, 108, 1241-9. DOI: 10.1111 /add.12152

Rubak, S., Sandbaek, A., Lauritzen, T., and Christensen, B. (2005). Motivational interviewing: a systematic review and meta-analysis. British Journal of General Practice, 55, 305-12.

Schneider,W.(1987). Ablenkung und Handlungskontrolle:EineKognitiv-MotivationalePerspektive. Unpublished Diploma thesis, University of Bielefeld, Bielefeld, Germany.

Shamloo, Z.S., and Cox, W.M. (2014). Information-enhancement and goal setting techniques for increasing adaptive motivation and decreasing urges to drink alcohol. Addictive Behaviors, 39, 1205-13. DOI: 10.1016/j.addbeh.2014.03.023

Sharbanee, J.M., Hu, L., Stritzke, W.G., Wiers, R.W., Rinck, M., and MacLeod, C. (2014). The effect of approach/avoidance training on alcohol consumption is mediated by change in alcohol action tendency. PLoS One, 9, e85855. DOI: 10.1371/journal.pone.0085855

Smart, R.G. (2007). Natural recovery or recovery without treatment from alcohol and drug problems as seen from survey data. In: H. Klingemann and L.C. Sobell (eds), Promoting Self-change from Addictive Behaviors: Practical Implications for Policy, Prevention, and Treatment New York: Springer Science + Business Media, pp. 59-71. 
Smith, D.G. and Ersche, K.D. (2014). Using a drug-word Stroop task to differentiate recreational from dependent drug use. CNS Spectrums, 19, 247-55. DOI: 10.1017/S1092852914000133

Smith, D.G., Simon Jones, P., Bullmore, E.T., Robbins, T.W., and Ersche, K.D. (2014). Enhanced orbitofrontal cortex function and lack of attentional bias to cocaine cues in recreational stimulant users. Biological Psychiatry, 75, 124-31. DOI: 10.1016/j.biopsych.2013.05.019

Sobell, L., C., Ellingstad, T.P., and Sobell, M.B. (2000). Natural recovery from alcohol and drug problems: methodological review of the research with suggestions for future directions. Addiction, 95, 749-64.

Stahl, B. (2013). Addicted nurses keep licenses. StarTribune, 32: A31, A38-9.

Swendson, J.D., Tennen, H., Carney, M.A., et al. (2000). Mood and alcohol consumption: an experience sampling test of the self-medication hypothesis. Journal of Abnormal Psychology, 109(2), 198-204.

Tabakoff, B. and Hoffman, P.L. (2013). The neurobiology of alcohol consumption and alcoholism: An integrative history. Pharmacology, Biochemistry and Behavior, 113, 20-37.

Tucker, J.A., Roth, D.L., Vignolo, M.J., and Westfall, A.O. (2009). A behavioral economic reward index predicts drinking resolutions: Moderation revisited and compared with other outcomes. Journal of Consulting and Clinical Psychology, 77, 219-28.

Tucker, J.A., Vuchinich, R.E., Black, B.C., and Rippens, P.D. (2006). Significance of a behavioral economic index of reward value in predicting drinking problem resolution. Journal of Consulting and Clinical Psychology, 74, 317-26.

Van Eerde, W. and Thierry, H. (1996). Vroom's expectancy models and work-related criteria: a metaanalysis. Journal of Applied Psychology, 81, 575-86.

Van Rensburg, K.J., Taylor, A., and Hodgson, T. (2009). The effects of acute exercise on attentional bias towards smoking-related stimuli during temporary abstinence from smoking. Addiction, 104, 1910-7. DOI:10.1111/j.1360-0443.2009.02692.x

Vanderschuren, L.J.M.J., and Everitt, B.J. (2005). Behavioral and neural mechanisms of compulsive drug seeking. European Journal of Pharmacology, 526, 77-88.

Vrieze, S.I., Vaidyanathan, U., Hicks, B.M., Iacono, W.G., McGue, M. (2014). The role of constraint in the development of nicotine, marijuana, and alcohol dependence in young adulthood. Behavior Genetics, 44, 14-24.

Waters, H. and Green, M.W. (2003). A demonstration of attentional bias, using a novel dual task paradigm, towards clinically salient material in recovering alcohol abuse patients? Psychological Medicine, 33, 491-8.

Wiers, R.W., Bartholow, B.D., van den Wildenberg, E., et al. (2007). Automatic and controlled processes and the development of addictive behaviors in adolescents: a review and a model. Pharmacology, Biochemistry and Behavior, 86, 263-83.

Wiers, C.E., Kuhn, S., Javadi, A.H. et al. (2013). Automatic approach bias towards smoking cues is present in smokers but not in ex-smokers. Psychopharmacology (Berlin), 229, 187-97. DOI: 10.1007/ s00213-013-3098-5

Wiers, R.W., Eberl, C., Rinck, M., Becker, E.S., and Lindenmeyer, J. (2011). Retraining automatic action tendencies changes alcoholic patients' approach bias for alcohol and improves treatment outcome. Psychological Science, 22, 490-7.

Wiers, R.W., Houben, K., Fadardi, J.S., van Beek, P., Rhemtulla, M., and Cox, W.M. (2015). Alcohol Cognitive Bias Modification training for problem drinkers over the web. Addictive Behaviors, 40, 21-6. DOI: $10.1016 /$ j.addbeh.2014.08.010

Wiers, C.E., Stelzel, C., Park, S.Q., et al. (2014). Neural correlates of alcohol-approach bias in alcohol addiction: the spirit is willing but the flesh is weak for spirits. Neuropsychopharmacology, 39, 688-97. DOI: $10.1038 / \mathrm{npp} .2013 .252$ 
Wiers, C.E., Stelzel, C., Gladwin, T.E., et al. (2015). Effects of cognitive bias modification training on neural alcohol cue reactivity in alcohol dependence. American Journal of Psychiatry, 72, 335-43. DOI: 10.1176/appi.ajp.2014.13111495

Wilcox, C.E., Dekonenko, C.J., Mayer, A.R., Bogenschutz, M.P., and Turner, J.A. (2014). Cognitive control in alcohol use disorder: deficits and clinical relevance. Reviews in the Neurosciences, 25, 1-24. DOI:10.1515/revneuro-2013-0054

Witkiewitz, K., Lustyk, M.K., and Bowen, S. (2013). Retraining the addicted brain: a review of hypothesized neurobiological mechanisms of mindfulness-based relapse prevention. Psychology of Addictive Behaviors, 27, 351-65.

Woud, M.L., Fitzgerald, D.A., Wiers, R.W., Rinck, M., and Becker, E.S. (2012). "Getting into the spirit": alcohol-related interpretation bias in heavy-drinking students. Psychology of Addictive Behaviors, 26, 627-32. DOI: 10.1037/a0029025

Woud, M.L., Pawelczak, S., Rinck, M., et al. (2014). Alcohol-related interpretation bias in alcoholdependent patients. Alcoholism: Clinical and Experimental Research, 38, 1151-9. DOI: 10.1111/ acer.12334

Wrosch, C., Scheier, M.F., and Miller, G.E. (2013). Goal adjustment capacities, subjective well-being, and physical health. Social and Personality Psychology Compass, 7, 847-60.

Zywiak, W.H., Stout, R.L., Longabaugh, R., et al. (2006a). Relapse-onset factors in Project MATCH: The Relapse Questionnaire. Journal of Substance Abuse Treatment, 31, 341-5.

Zywiak, W.H., Stout, R.L., Trefry, W.B., et al. (2006b). Alcohol relapse repetition, gender, and predictive validity. Journal of Substance Abuse Treatment, 30, 349-53. 